\title{
Assessment of groundwater quality in the Al- Burayhi and Hedran sub-basin, Taiz, Yemen - A GIS approach
}

\author{
Ramzy Naser, Mohammed El Bakkali, Nabil Darwesh, Khadija El Kharrim And Driss \\ Belghyti
}

Laboratory of Agro-Physiology, Biotechnology, Environment and Quality. Team Water, wastewater and Health. Faculty of science, university Ibn Tofail, 14000 Kenitra, Morocco

\begin{abstract}
In many parts of the world, groundwater sources are the single most important supply for the production of drinking water, particularly in areas with limited or polluted surface water sources. Fresh water has become a scarce commodity due to over exploitation and pollution of water. Many countries and international organizations, including Wolrd Health Organization, are seeking to promote people's access to safe drinking water. The situation in Yemen is no exception. Although we rely on groundwater significantly in our lives and our survival, we do not manage it in a way that ensures its sustainability and maintenance of pollution.

The objective of this study is to determine the suitability of the groundwater in Al Burayhi and Hedran sub-basin (one of the sub-basins of the Upper Valley Rasyan) as a source of drinking water in the shade of the expected deterioration due to natural processes (water interaction with rocks, semi-dry climate) and human activities.
\end{abstract}

Keywords: assessment of groundwater quality, the spatial distribution of groundwater pollution, Al Burayhi and Hedran sub-basin, Taiz and Yemen.

\footnotetext{
* Corresponding author:: ramzi_mh1@yahoo.com
} 


\section{Introduction}

Water is an essential element of life, and without water there will be no life for any living being. Water sources are either surface or groundwater. The source of water supplies in Yemen is mostly from groundwater accumulated during previous and current times. The problem of water in Yemen is that the quantities of water extracted from the ground are much higher than the quantities of recharge water for underground reservoirs. The increase in population and migration from villages to the city leads to pressure on water resources and contribute to their depletion. The situation in Taiz governorate is not different from the rest of Yemen, where groundwater has been depleted without any efforts to feed the aquifers and compensate for what is depleted through the establishment of barriers and dams. Worse still, humans reduce the natural recharge of groundwater as a result of various human activities on the surface of the earth and as a result of pollution that leads to the filling of pores and thus reduce water infiltration downwards and also change the course of water under the ground. Depletion of groundwater resources due to overexploitation and increased evaporation results in enhancement of dissolved constituents(Raju, Ashwani, and Anjali Singh 2017).

The objective of this study is to determine the suitability of the groundwater in Al Burayhi and Hedran sub-basin (one of the sub-basins of the Upper Valley Rasyan) as a source of drinking water in the shade of the expected deterioration due to natural processes (water interaction with rocks, semi-dry climate) and human activities.

\section{Material and Methods}

\subsection{Description of the Study area}

The study area is located in the north and north west of Taiz City, Yemen, between $(1498000-1516000)$ latitude and ( $370000-395000)$ longitude (Figure 1). The urbanization of Taiz City has reached some parts of the southern region of the study area (Figure 2). The solid waste landfill of Taiz, and the sedimentation ponds for domestic wastewater (disposed of in the sewerage system) are located in this area, There are also some industrial facilities and poultry farms in this area(Figure 3). Hydrology of study area is an extension of the hydrology of AL-Hawban and AL-Dhabab areas, that means, it is drainage area for these areas. The runoff water collects and flows into the northwestern part of the study area (Figure 3). 


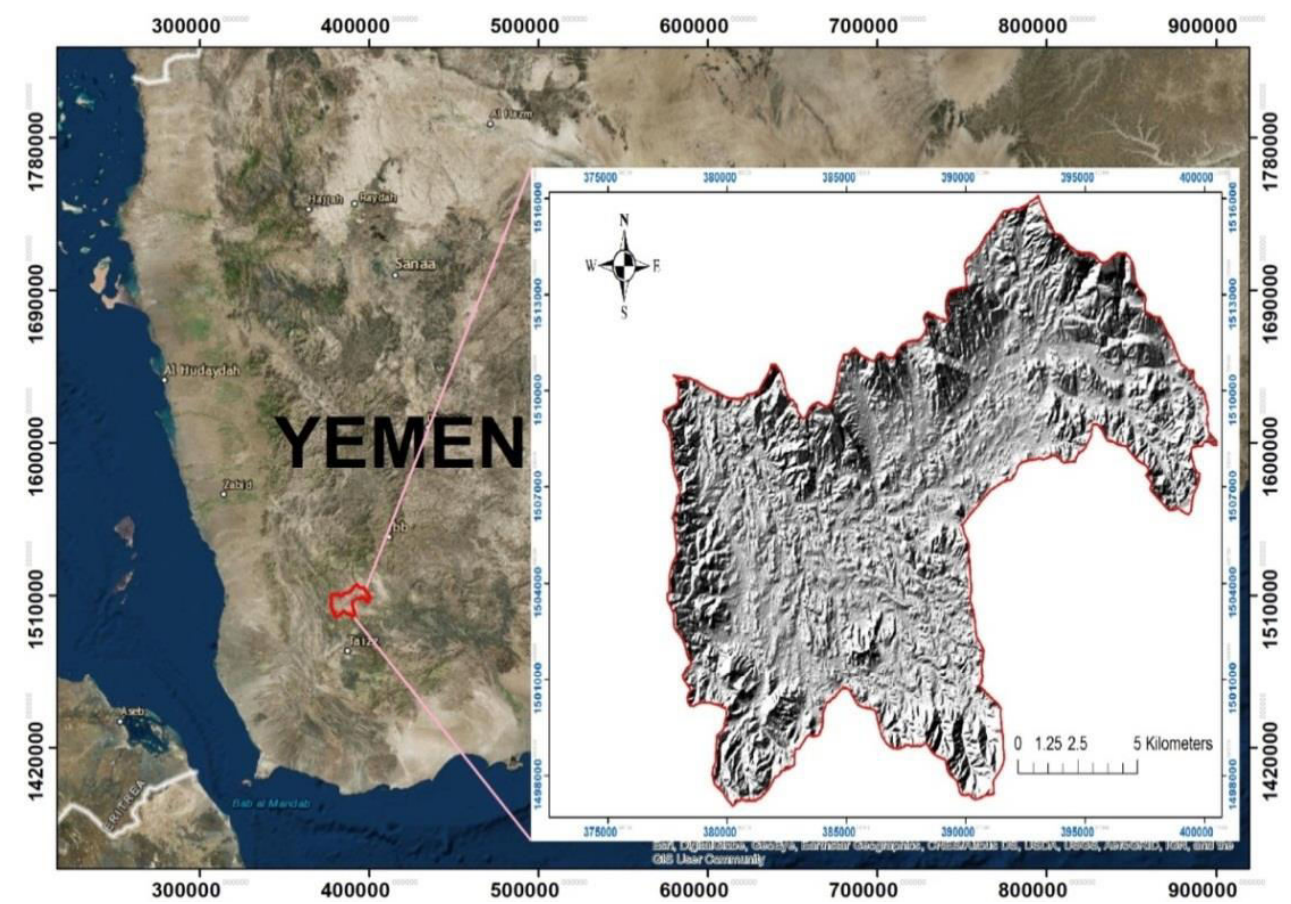

Fig.1. Location of the sudy area

\subsection{Inventory of sources of pollution in the study area.}

In order to try to understand the relationship between the quality of groundwater and the sources of pollution resulting from human activities, we have made an inventory of the sources of pollution in the study area and then represented them in the map (Figure 3). 


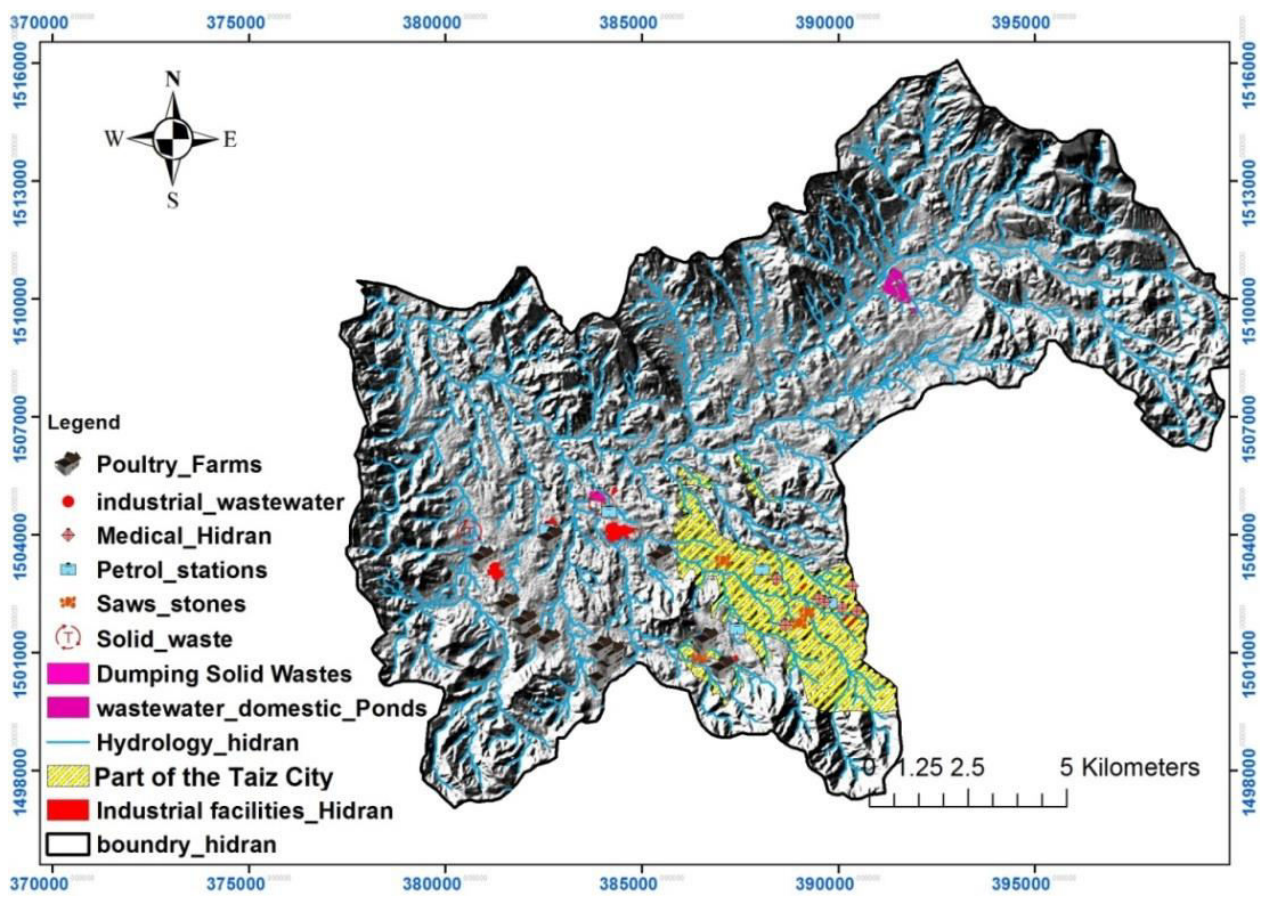

Fig.2. Spatial distribution of pollution sources in the study area

\subsection{Collection, transfer and analysis of samples}

Twenty-nine sampling points were selected from the different site in Al Burayhi and Hedran sub-basin based on the wells inventory in the study area to analyze their physical and chemical properties. Samples included all types of aquifers (sedimentary and volcanic) and all types of wells (bore well and dug well). Samples were taken only after the water was pumped from the well for a quarter of an hour and the electrical conductivity of the well water stabilized, so that samples could be taken directly from the aquifer. Sampling of wells was accompanied by information on wells. Groundwater samples were collected in new polyethylene bottles of $1000-\mathrm{ml}$ capacity after rinsed with distilled water and the water of the well, and then the bottles were filled with water to the top, practically leaving no air in, through months in August, September and October 2014. All samples were placed in an ice-box container and transferred to the laboratory within a maximum of 72 hours. Laboratory tests were performed for the analysis of samples for : Electrical conductivity $(\mathrm{EC}), \mathrm{pH}$, temperature $\left(\mathrm{T} \mathrm{C}^{\circ}\right)$, Total dissolved solids (TDS), Total Hardness (T.H), Total Alkalinity (T.ALK), Calcium (Ca), Magnesium $(\mathrm{Mg}$ ) Sodium $(\mathrm{Na})$, Potassium $(\mathrm{K})$ Bicarbonate (HCO 3), chloride $(\mathrm{Cl})$, Sulfate (SO4), Nitrate (NO3), Iron (Fe) and Fluoride (F). The collected samples were analyzed according to the method Assessment of Ground Water Quality described in "Standard methods for the examination of water and wastewater American Public Health Association (APHA). 


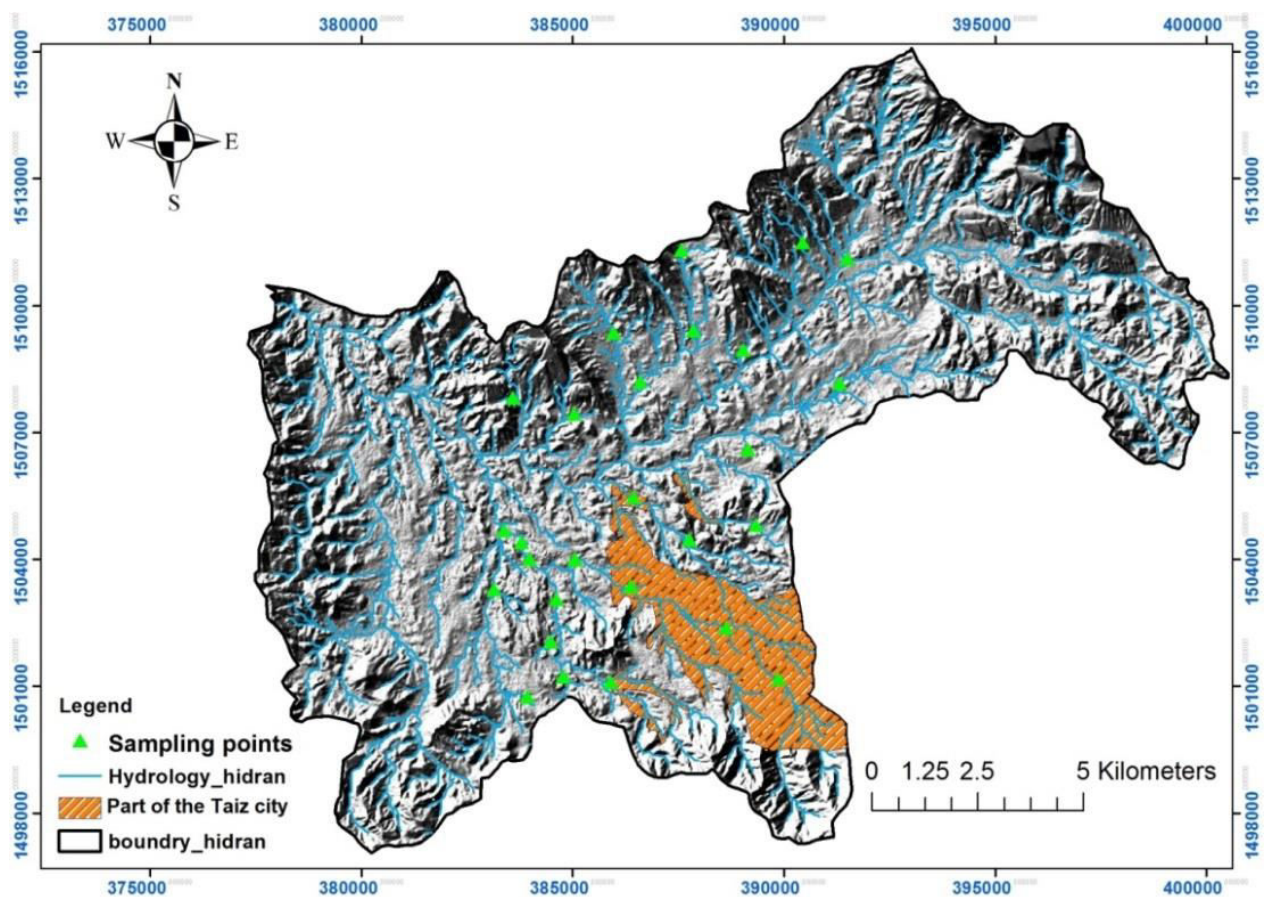

Fig.3. Hydrological study area and Sampling points

\section{Results and discussion}

Tableau 1 : Groundwater samples of the study area exceeding the permissible limits prescribed by WHO (2004) for drinking purpose.

\begin{tabular}{|c|c|c|c|c|}
\hline \multirow{2}{*}{$\begin{array}{l}\text { Water } \\
\text { quality } \\
\text { parameter }\end{array}$} & \multicolumn{2}{|c|}{ WHO (2004) } & \multirow{2}{*}{$\begin{array}{l}\text { Number of sample } \\
\text { desirable }\end{array}$} & \multirow{2}{*}{$\begin{array}{l}\text { Number of } \\
\text { samples } \\
\text { unfit }\end{array}$} \\
\hline & $\begin{array}{l}\text { Desirable } \\
\text { limit }\end{array}$ & $\begin{array}{l}\text { Maximum } \\
\text { permissible } \\
\text { limit }\end{array}$ & & \\
\hline $\mathrm{pH}$ & 6.5 & 8.5 & 29 & 0 \\
\hline $\mathrm{EC}(\mu \mathrm{S} / \mathrm{cm})$ & 500 & 2500 & 8 & 21 \\
\hline TDS (mg/l) & 500 & 1500 & 7 & 22 \\
\hline $\mathrm{TH}(\mathrm{mg} / \mathrm{l})$ & 100 & 500 & 5 & 24 \\
\hline $\mathrm{Ca}^{2+}(\mathrm{mg} / \mathrm{l})$ & 75 & 200 & 18 & 11 \\
\hline $\mathrm{Mg}^{2+}(\mathrm{mg} / \mathrm{l})$ & 50 & 150 & 12 & 17 \\
\hline $\mathrm{Na}^{+}(\mathrm{mg} / \mathrm{l})$ & - & 200 & 4 & 25 \\
\hline $\mathrm{K}^{+}(\mathrm{mg} / \mathrm{l})$ & - & 12 & 25 & 4 \\
\hline $\mathrm{Cl}^{-}(\mathrm{mg} / \mathrm{l})$ & 200 & 600 & 12 & 17 \\
\hline $\mathrm{SO}_{4}{ }^{2-}(\mathrm{mg} / \mathrm{l})$ & 200 & 400 & 23 & 6 \\
\hline $\begin{array}{l}\mathrm{HCO}_{3}^{-} \\
(\mathrm{mg} / \mathrm{l})\end{array}$ & - & 500 & 1 & 28 \\
\hline $\mathrm{NO3}^{-}(\mathrm{mg} / \mathrm{l})$ & - & 50 & 26 & 3 \\
\hline $\mathrm{Fe}(\mathrm{mg} / \mathrm{l})$ & 0.3 & 1 & 28 & 1 \\
\hline $\mathrm{F}^{-}(\mathrm{mg} / \mathrm{l})$ & 1 & 1.5 & 5 & 24 \\
\hline
\end{tabular}

Almost all the samples showed very high concentrations of both Electrical Conductivity; Total dissolved solid; Total hardness; Magnesium; Sodium; Chloride; Bicarbonate and Fluoride. By comparing the results obtained with the standard specifications of Yemen 
and the World Health Organization standards, it became clear that the Groundwater in most parts of the study area is contaminated and unfit for drinking. The high concentration of contamination at the level of Al Burayhi and Hedran sub-basin could be explained by: The distribution of major ions largely depends on the type of geological formations in contact with the groundwater flowing through, Irrigation return flow, disposal of wastewater domestic and industries, Runoff and evaporation because of climate semi-arid.

The problem of water in the city of Taiz and surrounding areas is a complex problem. There is an extraction of quantities of water in excess of the actual need and there is squandering of these water because of the old and dilapidated network of water supplies (there are a large loss of water), and on the other hand irrigation in various areas by flooding, which consume large quantities of groundwater and beyond the actual need To irrigate the earth. Some of these water evaporate as a result of the semi-arid climatic conditions in the region, especially as irrigation is most often done at times when evaporation is high because of the heat of the sun, some of which go back down and salinity has been concentrated.

The other side of the water problem in and around Taiz is the contamination of groundwater in these areas due to the lack of solid and liquid waste management for various urban and industrial activities. The final outcome of these misdeeds eventually led to the inappropriateness of drinking water from this sub-basin.

\section{References}

1. Raju, Ashwani, and Anjali Singh (2017): "Assessment of Groundwater Quality and Mapping Human Health Risk in Central Ganga Alluvial Plain, Northern India." Environmental Processes : p1-23.

2. APHA (1995): Standard methods for the examination of water and waste water, 19th edn. American Public Health Association, Washington, DC

3. WHO (2004): Guidelines for drinking water quality. World Health Organisation, Geneva 